\title{
Necrotizing soft tissue infection of the chest wall
}

\author{
Whitney Brandt, ${ }^{1}$ Mark W Maxfield, ${ }^{1}$ Anthony W Kim, ${ }^{1,2}$ Kimberly A Davis ${ }^{1,3}$
}

${ }^{1}$ Department of Surgery, Yale School of Medicine, New Haven, Connecticut, USA ${ }^{2}$ Section of Thoracic Surgery, Yale School of Medicine, New Haven, Connecticut, USA ${ }^{3}$ Section of General Surgery, Trauma, and Surgical Critical Care, Yale School of Medicine, New Haven, Connecticut, USA

\section{Correspondence to}

Dr Kimberly A Davis; Kimberly. Davis@yale.edue000005

Received 6 April 2016 Revised 19 April 2016 Accepted 20 April 2016
To cite: Brandt $W$ Maxfield MW, Kim AW, et al. Trauma Surg Acute Care Open Published Online First: [please include Day Month Year] doi:10.1136/ tsaco-2016-000005
A 53-year-old man with hypertension, anxiety, and active alcohol abuse presented to the emergency room with increasing lethargy and shortness of breath. He reported a 9-day history of left-sided chest pain and erythema, which had worsened over the 4 days prior to admission. Review of systems was positive for fever, chills, fatigue, cough, chest tightness, and malaise. Notably, 12 days prior to his presentation, he was admitted after an assault and sustained facial fractures and lacerations; physical examination and CT of the chest/abdomen/pelvis at that time were negative for other injuries.

On re-presentation, he was tachycardic and normotensive. His left chest wall was warm, erythematous, and diffusely tender with crepitus that extended into the axilla. Initial laboratory data demonstrated hyponatremia (serum sodium $130 \mathrm{mEq} / \mathrm{L}(135-145 \mathrm{mEq} / \mathrm{L}))$, an anion gap of $20 \mathrm{mEq} / \mathrm{L}$ (3-11 mEq/L), and hypovolemia, with a blood urea nitrogen (BUN) of $42 \mathrm{mg} / \mathrm{dL}(7-20 \mathrm{mg} /$ $\mathrm{dL})$ and a creatinine of $0.9 \mathrm{mg} / \mathrm{dL}(0.5-1.2 \mathrm{mg} /$ $\mathrm{dL})$. He had a leukocytosis of 17500 cells $/ \mu \mathrm{L}$ (4500-10 000 cells $/ \mu \mathrm{L})$ with a marked left shift (15\% bands, 56\% neutrophils). Blood cultures were collected. A CT of the chest/abdomen/pelvis was obtained and demonstrated a $23 \mathrm{~cm} \times 10$ $\mathrm{cm} \times 18 \mathrm{~cm}$ collection of air and fluid in the left chest wall extending into the left axilla. A second collection was identified in the mediastinum and pleural space with concomitant collapse of the left lower lobe and almost the entire left upper lobe (figure 1).

\section{WHAT WOULD YOU DO?}

A. Admit to the intensive care unit (ICU), start antibiotics, and observe?

B. Place a left-sided chest tube?

C. Proceed to the operating room?

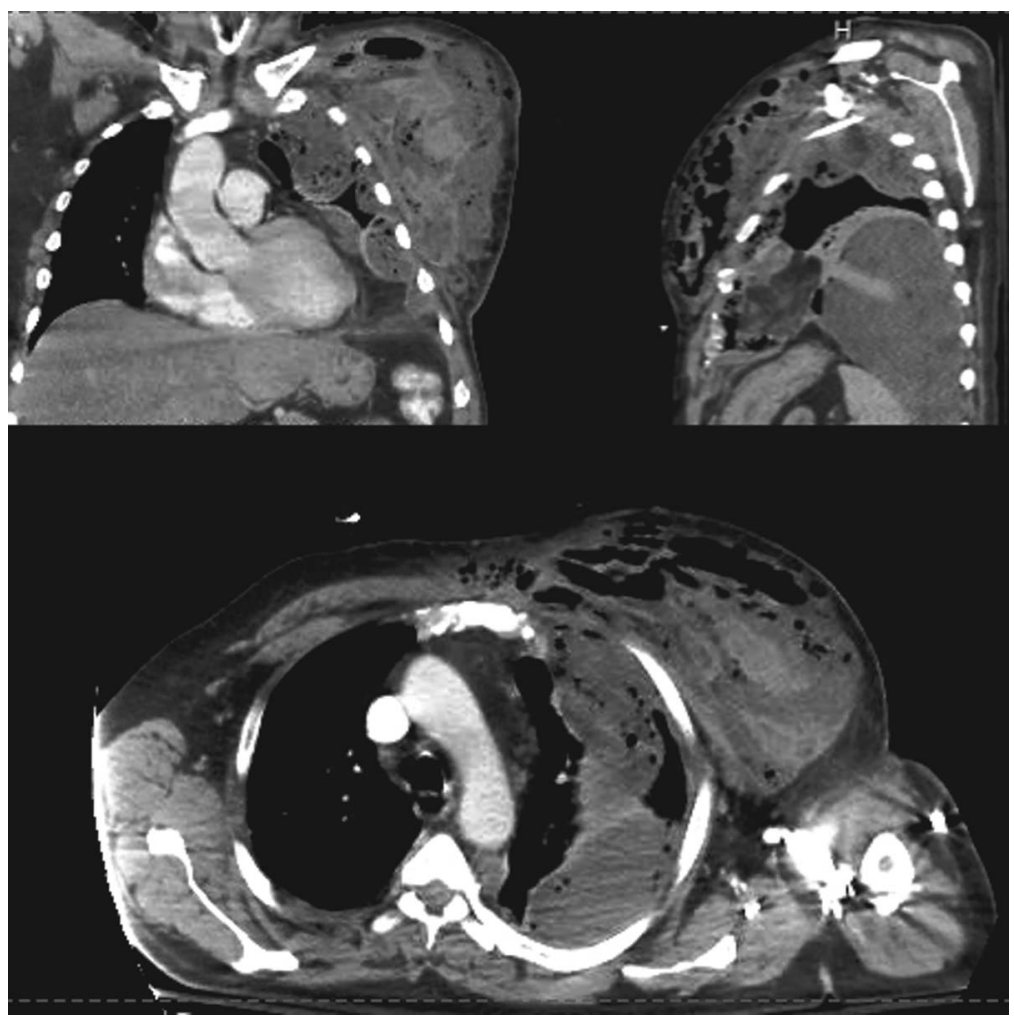

Figure 1 CT scan on the day of presentation. There is a $23 \times 10 \times 18 \mathrm{~cm}$ heterogeneous collection containing air in the subcutaneous soft tissues. There is extension of the collection into the thoracic cavity, involving the pleural space as well as the upper mediastinum. The left lower lobe and lingula are collapsed, and only the upper left lung remains aerated. The tracheobronchial tree is unaffected. 


\section{WHAT WE DID AND WHY}

\section{Correct answer C}

The patient was diagnosed with a necrotizing soft tissue infection (NSTI) of the left chest wall with associated empyema. Vancomycin and piperacillin/tazobactam were administered, and he was taken to the operating room for exploration and debridement. He was found to have extensive necrosis of the subcutaneous tissues, pectoralis major, and most of his pectoralis minor, all of which were debrided. The infection was contiguous with a large empyema. The chest wall was packed and a chest tube placed. Cultures grew methicillin-resistant Staphylococcus aureus (MRSA). He underwent daily serial debridements of his chest wall and decortication on day 3. Final pathology was consistent with a NSTI. His chest wall defect was managed with a negative pressure dressing (figure 2). He was discharged to a rehabilitation facility with a negative pressure dressing to the left chest 18 days after presentation. After 2 months, he underwent a latissimus dorsi flap for chest wall reconstruction (figure 3).

NSTIs are rare but serious infections associated with a significant morbidity and mortality. Despite improvements in the diagnosis and treatment, mortality remains high (16.9-29\%). Early recognition and prompt surgical intervention decrease mortality. Factors that suggest a necrotizing infection include exquisite tenderness to palpation, marked erythema, crepitus, and bullae. Patients often manifest signs of sepsis and septic shock. Laboratory abnormalities include leucocytosis, neutrophilia, and hyponatremia.

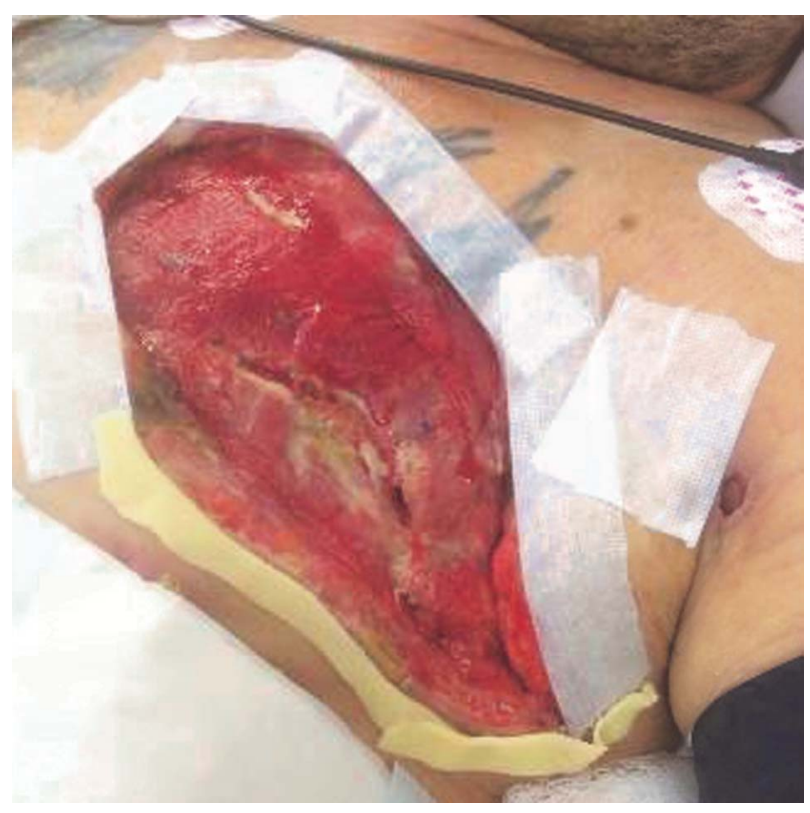

Figure 2 The patient underwent serial debridements and pleural cavity drainage. After surgical control of the necrotizing soft tissue infection, the chest wall wound healed well and was treated with a negative-pressure dressing changes. Here is a photo of the wound 5 days after initiation of wound vacuum assisted closure (VAC) therapy. There is extensive granulation tissue at the base of the wound and no residual necrotic tissue.

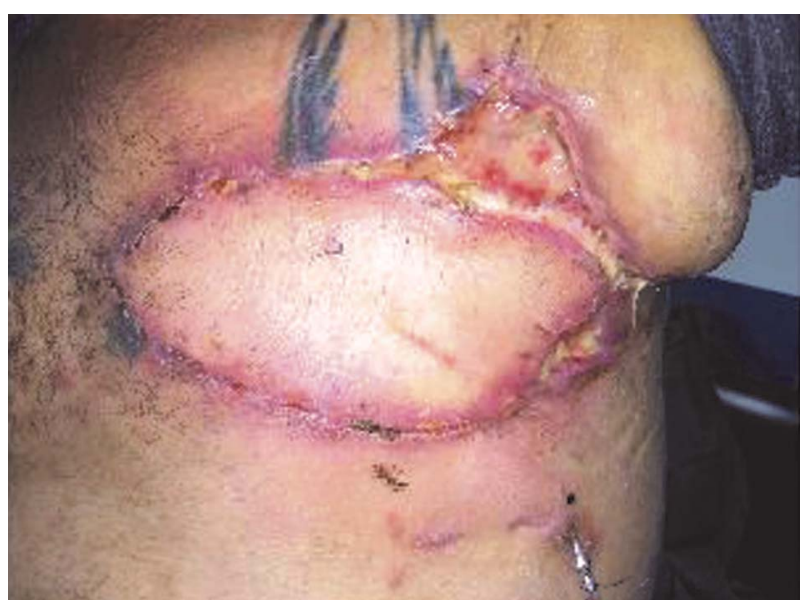

Figure 3 Two months after initial presentation. Left chest wall following reconstruction with a pedicled latissimus dorsi flap.

Few reports describe NSTI of the chest, most of which are due to penetrating trauma or chest tube placement. It is possible that this patients' infection originated from an infected hematoma or pneumonia, which expanded outward from the pleural space into the chest wall. The current literature cites an exceptionally high mortality after NSTI of the chest wall (60-89\%). The higher mortality of chest wall NSTI is due to the impact of aggressive debridement on chest wall mechanics. Maintenance of chest wall integrity improves outcomes and should be attempted in order to allow proper ventilation and recovery.

The development of NSTI after empyema or hemothorax is extremely rare. It is prudent to drain empyemas to facilitate recovery, yet some patients have pleural collections that remain undrained with satisfactory clinical outcome. To the best of our knowledge, there are no data that estimate the risk of development of NSTI after empyema whether drained or undrained.

Overall, this case represents an extremely unique presentation of chest wall NSTI. While most cases of NSTI of the chest are incited by iatrogenic procedures, this NSTI developed secondary to a presumed undrained empyema, which may have been related to pneumonia with superinfection of a small hemothorax. Currently, little data exist on the relationship between empyema and subsequent NSTI. Future studies should evaluate this relative risk in order to help guide the future management of such pleural collections and decrease the morbidity and mortality from highly lethal chest wall NSTIs.

Contributors All members of the team provided care for the patient in question. WB and MWM performed the literature review and drafted the manuscript. AWK and KAD provided critical review.

\section{Competing interests None declared.}

Provenance and peer review Not commissioned; internally peer reviewed.

Open Access This is an Open Access article distributed in accordance with the Creative Commons Attribution Non Commercial (CC BY-NC 4.0) license, which permits others to distribute, remix, adapt, build upon this work non-commercially, and license their derivative works on different terms, provided the original work is properly cited and the use is non-commercial. See: http://creativecommons.org/ licenses/by-nc/4.0/ 